\title{
A Time-Delay Suppression Technique for DPWM Control Circuit
}

\author{
Yoichi Ishizuka, Fumitoshi Hirose, Yusuke Yamada and Hirofumi Matsuo \\ Nagasaki University \\ 1-14 Bunkyo-machi, Nagasaki, JAPAN \\ isy2@nagasaki-u.ac.jp
}

\begin{abstract}
A proposed design of a low-cost digital pulse width modulation (DPWM) control circuit for non-isolated DC-DC converter without A/D converter is described. Also, propsed realtime PID control technique for DPWM is described. Some experimental results and simulation results are revealed the proposed circuit and scheme. The purpose of this research is striking a balance between minimizing cost increase by digitalizing of the control circuit of DC-DC converter and speeding up the control circuit.
\end{abstract}

\section{INTRODUCTION}

Recently, power management has been introduced to improve the power efficiency of Micro Processing Unit (MPUs), Field Programmable Gate Array (FPGAs) and Digital Signal Processor (DSPs). The power management system includes a full operation mode, standby mode, and sleep mode. The clock frequency, core voltage and/or core current are changed in each mode accordingly. As a result, the output current of the point-of-load (POL) DC-DC converters is intermittent and has a high slew rate. A low output voltage, a large output current and a high speed response are required for the POL [1]. In such a condition for the control circuit, highly accurate and high-speed control demands that the tolerance of the output voltage becomes internally severe, advanced by speed-up and lowering of the voltage of the MPUs, FPGAs and DSPs [2,3]. A general control method is pulse width modulation (PWM) control with PID. Generally, such control circuits are composed with analog circuits and/or simple combination digital circuits.

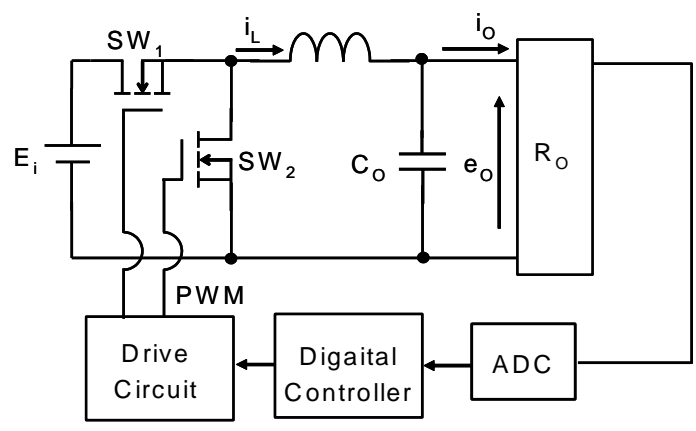

Figure 1. Common digital control DC-DC converter.
In these days, robustness or flexible controls for versatile conditions are demanded which cannot accomplished with analog control circuit. For the control purpose, DPWM control is a one of appropriate technique [4-6].

Digital control or DPWM can accomplish robust and flexible power control with soft-tuned parameters and will become popular control technique.

Although, there are some disadvantages in cost and speed, against analog control circuit.

Especially, A/D converter circuit, which doesn't need for analog control, is the one of the key circuits which effects on cost and speed. Generally, A/D converter is located in front of digital controller as shown in Fig. 1. Therefore, the transition speed of A/D converter directly effects on the response speed of the control circuit. And, the cost and speed are always trade off problem. This problem is especially serious in POL DCDC converter which is required to design the control circuit in relatively low-cost and high speed control response. Moreover, generally, there is sample-hold circuit in front of A/D converter which degrades the response speed.

A delay in any feedback system degrades the stability and damping of the system [7]. Especially, in DPWM, if a total of the delays described in above become larger than on-term of one switching period, a factor of $\mathrm{A} / \mathrm{D}$ converter becomes $\mathrm{Vq} / \mathrm{Z}$ shown in Fig. 2 where $\mathrm{Vq}$ is a coefficient constant.

An objective of this paper is to design high speed and low cost voltage sensing circuit for DPWM control circuit for DCDC converter. And, also real-time PID control method is proposed. In Sec. II, the details of proposed system are described. In Sec. III, the some characteristics of the system are confirmed with experimental results. Finally, in Sec. IV, the summary is described.

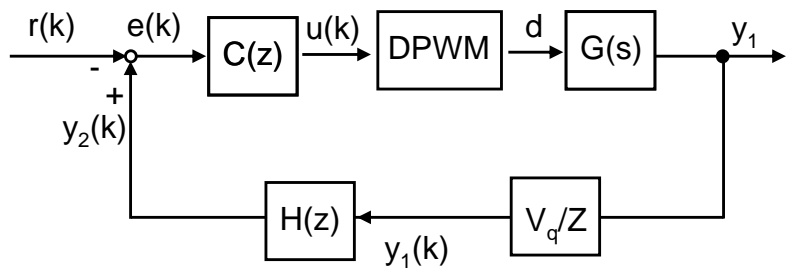

Figure 2 Control System. 


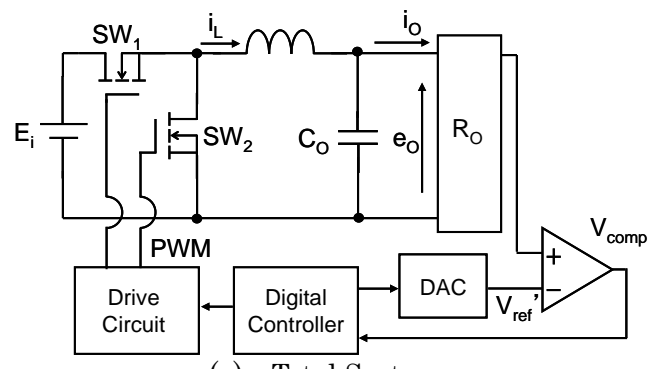

(a) Total Systems.

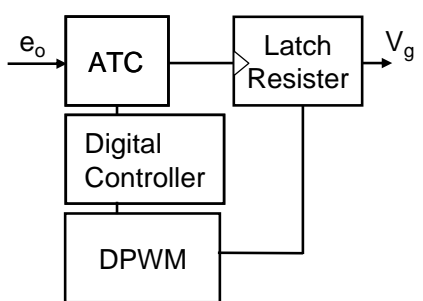

(b) Control blocks.

Figure 3. Proposed DPWM Control DC-DC converter

\section{Proposed System}

We propose a scheme of a digital control and DPWM circuit for DC-DC converter without A/D converter shown in Figs.3 and 4, respectively. In this proposed control circuit, most components are digital components. Analog components for the control circuit are essentially only D/A converter and analog comparator. Theoretical waveforms of each part are shown in Fig. 5.

The control circuit is composed of three major blocks.

\section{A. Analog-Timing Converter (ATC)}

The first block is ATC block which detects the output voltage $e_{o}$ and outputs the detected signal to latch register. The maximum output value of D/A converter DAC is set as a sum of the output reference voltage of DC-DC converter $V_{\text {ref }}$ and margin $\alpha(>0)$. A digital staircase waveform data, pre-stored in memory Memory1, is output to DAC synchronized with a system clock, and converted analog staircase waveforms $V_{\text {ref }}$ ' is compared with $e_{o}$. As soon as $V_{r e f}{ }^{\prime}>e_{o}$, the comparator outputs high.

\section{B. PID control with Look-up Table}

$u(k)$ which is output from Memory2 is calculated by general PID digital control laws as

$$
u(k)=u_{R e f}+K_{P} e(k)+K_{I} n_{I}(k)+K_{D}(e(k)-e(k-1))
$$

where $u_{\text {Ref }}$ is a reference value of $u(k), e(k)$ is an digitalized error value between $r$ which is digitalized reference voltage $V_{\text {ref }}$ in switching term $k$, and $n_{I}(k)=n_{I}(k-1)+e(k) . K_{P}, K_{I}$ and $K_{D}$ are a proportional gain, an integral gain and an derivative gain, respectively.

Equation (1) can be transformed to

$$
\begin{aligned}
u(k) & =u_{\text {Ref }}-\left(K_{P}+K_{I}\right) r \\
& +A\left\{y_{2}(k)+\frac{K_{I}}{A} n_{I}(k-1)-\frac{K_{D}}{A} y_{2}(k-1)\right\}
\end{aligned}
$$

where $A=K_{P}+K_{I}+K_{D}$ and $y_{2}(k)$ is digitalized output voltage $e_{o}$ in switching period $k$.

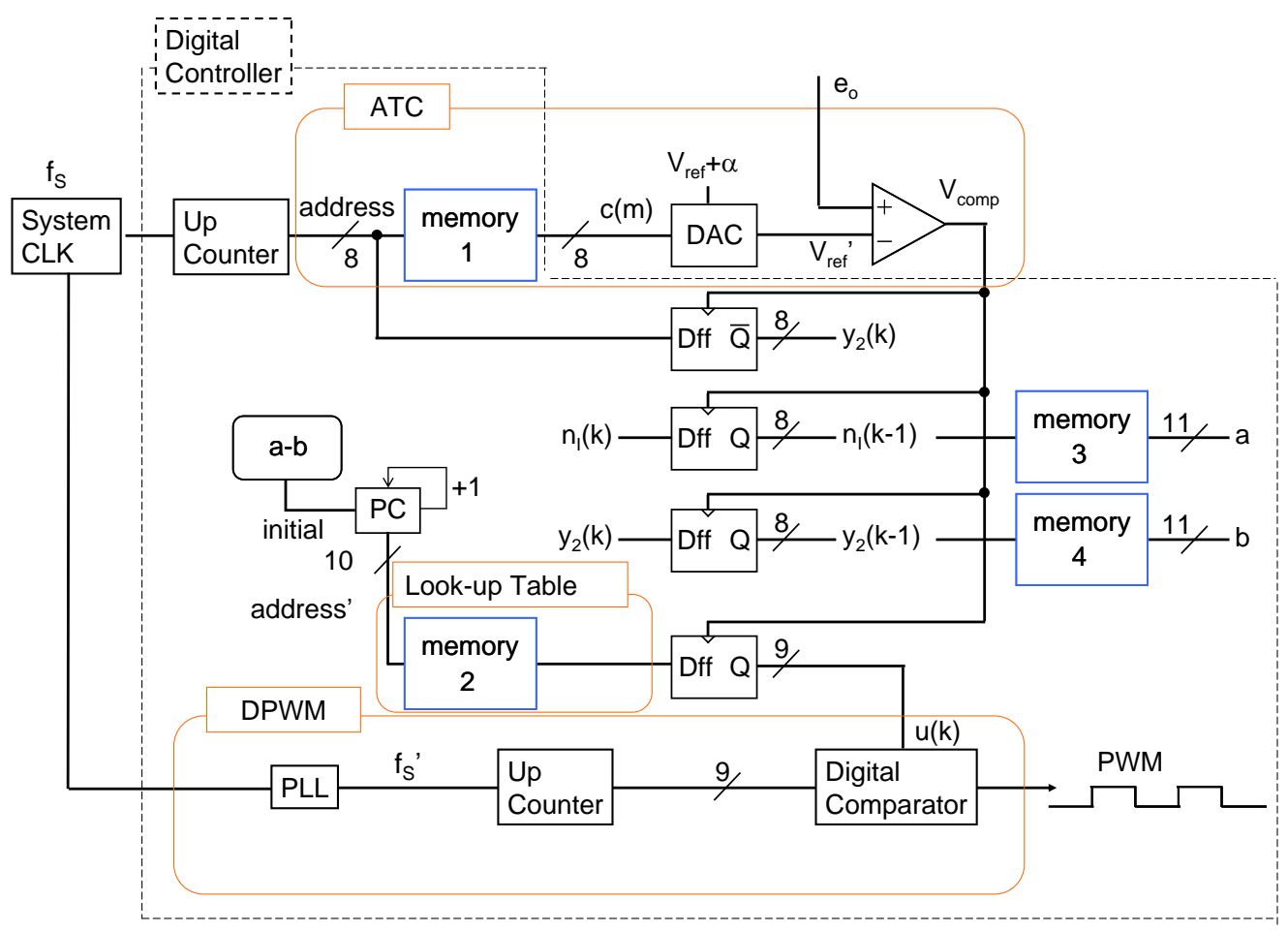

Figure.4. Proposed digital control circuit. 
In Fig. 4,

$$
\begin{aligned}
& a=\frac{K_{I}}{A} n_{I}(k-1), \\
& b=\frac{K_{D}}{A} y_{2}(k-1) .
\end{aligned}
$$

Memory3 and Memory4 store $a$ and $b$, respectively.

In (2), $a-b$ in the term $k$ is pre-calculated in the term $k-1$ and the obtained value becomes the initial value of programmable counter PC of the term $k$. And, address' which indicates address of Memory2 is incremented with system clock and $u(k)$ is called from Memory2, simultaneously.

$$
\operatorname{address}^{\prime}=y_{2}(k)+a-b .
$$

From (2) and (5),

$$
u(k)=u_{R e f}-\left(K_{P}+K_{I}\right) r+A_{\left\{\text {adress }^{\prime}\right\}} .
$$

Therefore, $u(k)$ is determined as soon as $y_{2}(k)$ is detected.

\section{DPWM}

In this system, on-term $T_{o n}(k)$ of DPWM signal is decided by $u(k)$, which is normalized $T_{o n}(k)$, and system clock frequency $f_{S}$ 'as

$$
T_{\text {on }}(k)=u(k) / f_{s},
$$

$u(k)$ is decided by latched value of Memory2.

In parallel with the processing of ATC block, the $u(k)$ is called with system clock and latched by ATC output as trigger.

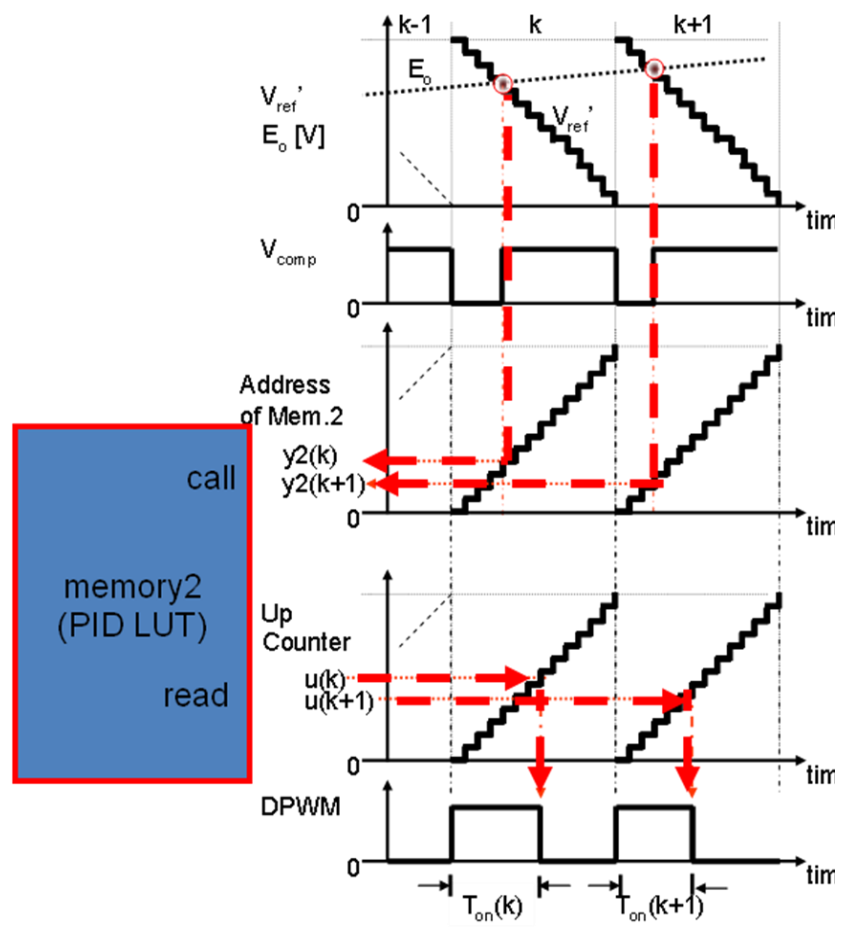

Figure 5. Theoretical waveforms.

\section{SENSING RESOLUTION}

\section{A. Resolution Increasing}

As described in previous section, all blocks are synchronized with only one clock source. From this advantage, all blocks are modified in easy way.

In this paper, voltage sense resolution increase of output voltage is proposed.

In proposed system, R-2R ladder type D/A converter is used. The output voltage is set between $V_{r e f}{ }^{+}\left(=V_{r e f}+\alpha\right)$ and $V_{\text {ref }}{ }^{-}$.

Therefore,

$$
V_{r e f}^{\prime}=\frac{c(m)}{2^{n}}\left(V_{r e f}^{+}-V_{r e f}^{-}\right)+V_{r e f}
$$

where $\mathrm{n}$ is bits. Also, least significant bit (LSB) voltage $a_{L S B}$ becomes

$$
a_{L S B}=\frac{1}{2^{n}}\left(V_{r e f}^{+}-V_{r e f}^{-}\right)
$$

In this paper, $V_{\text {ref }}$ is set to $V_{\text {ref }} / 2$. Almost $n+1$ bits resolution can be realized by $\mathrm{n}$ bits digital system as shown in Table I.

\section{B. Sensing Time Delay}

With this method, sensing time is increased. To avoid the time delay, the reference voltage waveform data pre-set in memory $1 V_{\text {ref }}$ 'is modified as shown in Fig. 6.

\section{PROTOTYPE CIRCUIT EXPERIMENTS}

\section{A. Experimental Conditions}

Some experiments are performed to verify the scheme. The proposed controller with prototype circuit is shown in Fig. 7. The digital controller part is designed in FPGA Altera Stratix with Quartus II. 149 logic elements and 1 PLL block are used.

Table I. Relations between parameter and quantization error of D/A Converter

\begin{tabular}{|l|r|r|r|r|}
\cline { 2 - 5 } \multicolumn{1}{c|}{} & \multicolumn{1}{c|}{$\begin{array}{c}\text { bits } \\
\mathrm{n}[\mathrm{bit}]\end{array}$} & \multicolumn{2}{|c|}{$\begin{array}{c}\text { Reference voltage } \\
\mathrm{V}_{\text {ref }}+[\mathrm{V}]\end{array}$} & $\begin{array}{c}\text { LSB vol- } \\
\text { tage value } \\
\text { aLSB }\end{array}$ \\
\hline [3] $[\mathrm{V}]$ & 8 & 1.7 & 0 & 6.64 \\
\hline [3] with 9bits & 9 & 1.7 & 0 & 3.32 \\
\hline Proposed method & 8 & 1.7 & 0.75 & 3.71 \\
\hline
\end{tabular}

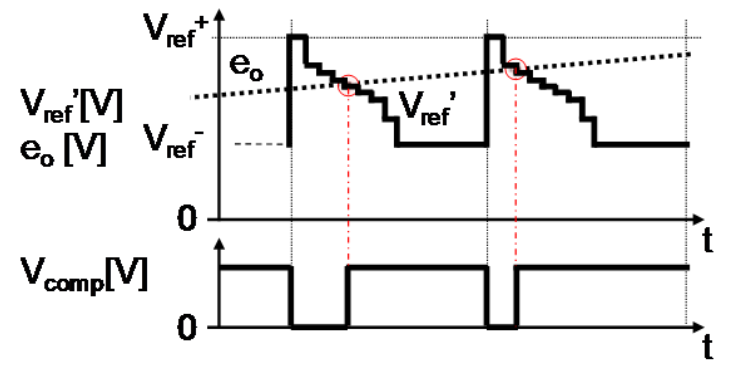

Figure 6. Modified reference voltage waveforms 
TABLE II.

Experimental conditions

\begin{tabular}{c|c}
\hline Input voltage $\mathrm{E}_{\mathrm{i}}$ & $2-8 \mathrm{~V}$ \\
\hline Output voltage $\mathrm{E}_{\mathrm{o}}$ & $1.5 \mathrm{~V}$ \\
\hline Output current $\mathrm{I}_{\mathrm{o}}$ & $0-5 \mathrm{~A}$ \\
\hline Switching frequency $\mathrm{f}_{\mathrm{S}}$ & $130 \mathrm{kHz}$ \\
\hline Choke inductor $\mathrm{L}$ & $17 \mu \mathrm{F}$ \\
\hline Output capacitor $\mathrm{C}_{\mathrm{o}}$ & $500 \mu \mathrm{F}$ \\
\hline Proportional gain $\mathrm{K}_{\mathrm{P}}$ & 25 \\
\hline Integral gain $\mathrm{K}_{\mathrm{I}}$ & $0.3-1.5$ \\
\hline $\mathrm{V}_{\text {ref }}+\alpha$ & $1.7 \mathrm{~V}$ \\
\hline $\mathrm{V}_{\text {ref }}{ }^{-}$ & $0.75 \mathrm{~V}$ \\
\hline System CLK & $33.3 \mathrm{MHz}$ \\
\hline
\end{tabular}

All memory blocks, Memory1, Memory2, Memory3 and Memory4, are including in the logic elements.Intersil CA3338MZ is used as 8bit DAC. National Semiconductor LMV7219 is used as an analog comparator.

The DC-DC converter topology is basically same as Fig. 2 . The experimental conditions are shown in Table II.

\section{B. Experimental Results}

The static experimental waveforms are shown in Fig. 8.

From this result, it is able to confirm that the output voltage sensing is done within the on-width of PWM signal.

\section{Dynamic Characteristics}

Figure 9 and 10 show dynamic characteristics with load current $i_{o}$ changing between $0.5 \mathrm{~A}$ and $2.5 \mathrm{~A}$, respectively. The mixed-signal oscilloscope Textronix MSO4034 is used to measure analog and digital signal, coinstantaneously. The load current changing is performed with $1 \mathrm{kHz}$ driven power MOSFET parallely-connected to load resistance. Yellow and Blue line shows the output voltage and the output current, respectively. The 9 bits pulse waveforms shown at the bottom of Fig. 9 are calculated DPWM of FPGA.

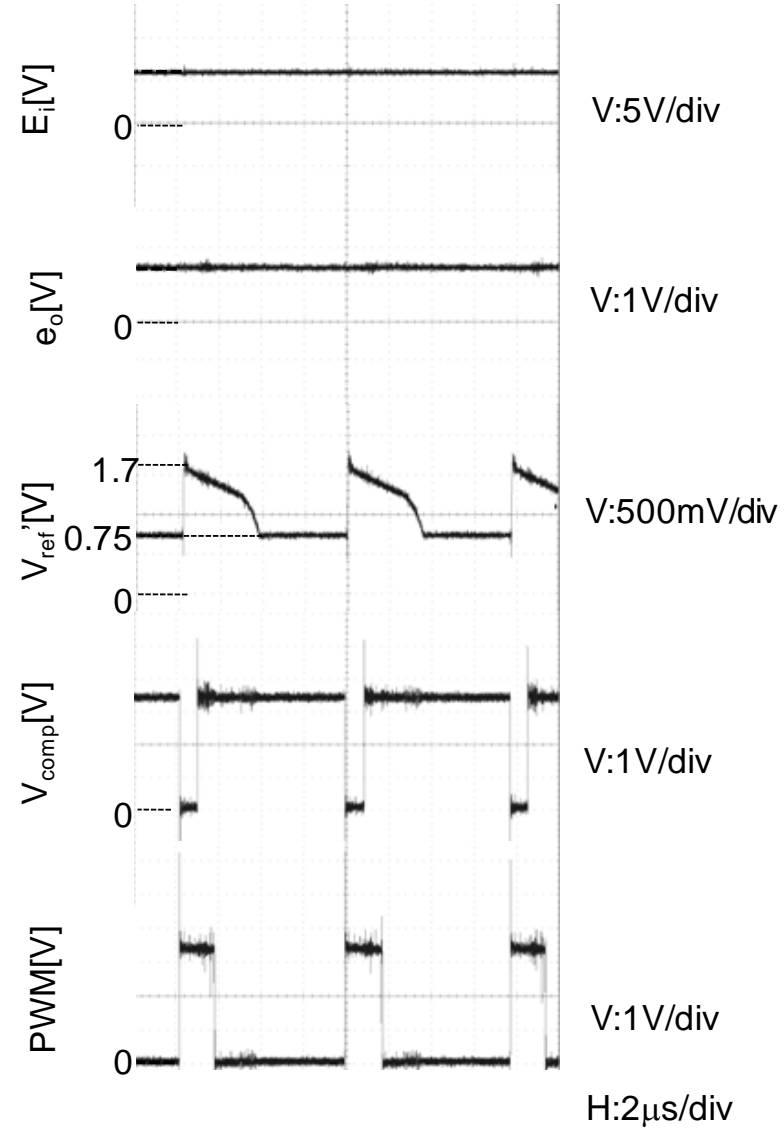

Fig. 8. Experimental waveforms

Figure 9 shows the sudden load current increasing results. From this results, after the $1 \mu$ s voltage drop, the output voltage immediately recover to the reference voltage.

Figure 10 shows the sudden load current decreasing results. From this results, after the $1 \mu$ s voltage rising, the output voltage immediately recover to the reference voltage.

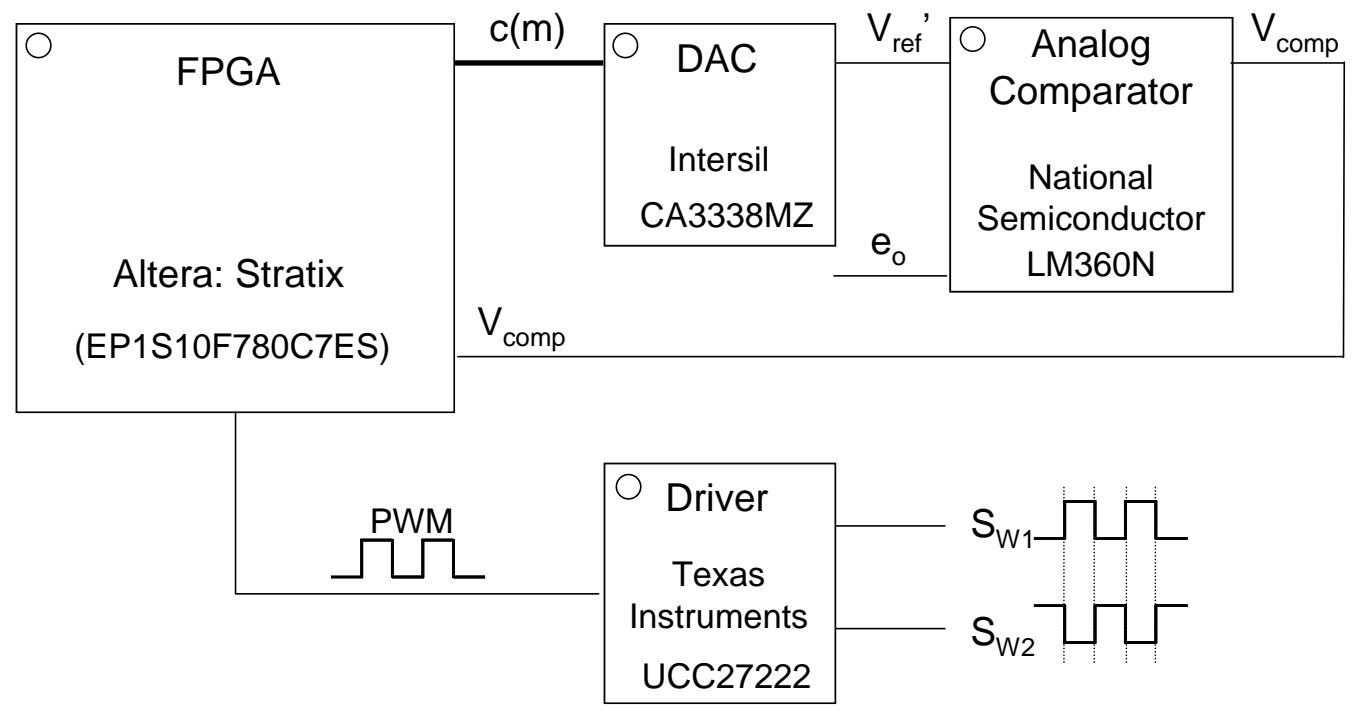

Figure 7. Prototype proposed control circuit. 


\section{CONCLUSION}

This paper describes a digital PWM controller IC without A/D converters. The analog timing converter (ATC) is proposed for output voltage sensing. In this system, analog circuit are realized with an comparator and an D/A converter.

\section{REFERENCES}

[1] A. Ichinose, Y. Ishizuka, and H. Matsuo: "A Fast Response DC-DC Converter with DPWM Control”, Technical Report of IEICE, vol. 105, no. 538, EE2005-58, pp. 67-71 (2006-1) (in Japanese)

[2] Y. Ishizuka, M. Ueno, I. Nishikawa, A. Ichinose, and H. Matsuo: "A Low-Delay Digital PWM Control Circuit for DC-DC Converters", IEEE Applied Power Electronics Conference (APEC'07), pp.579-584, Anaheim, California (2007- 2)

[3] M. Nishi, Y. Asako, Y. Ishizuka, and H. Matsuo: “A control

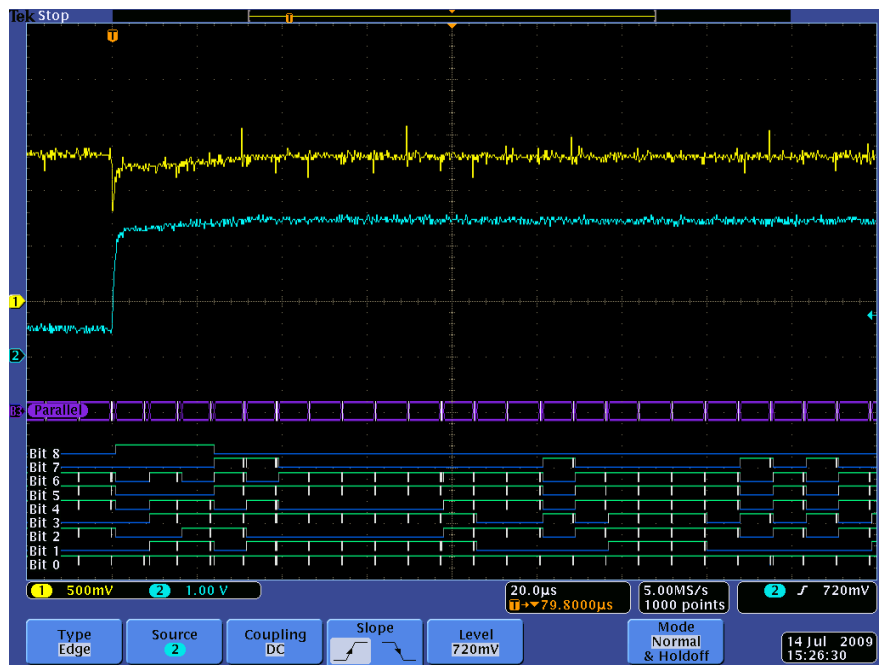

(a) $\mathrm{H}: 20 \mu \mathrm{s} / \mathrm{div}$ circuit composition and several characteristics of the proposed DPWM controlled POL", Technical Report of IEICE, vol. 107, no. 430, EE2007-46, pp. 13-18 (20081) (in Japanese)

[4] Edward Lam, Robert Bell, and Donald Ashley: "Revolutionary Advances in Distributed Power Systems", in Proc. IEEE APEC '03, 1.5 (2003)

[5] A.V.Peterchev, and S.R.Sanders: "Quantization Resolution and Limit Cycling in Digitally Controlled PWM", IEEE Trans. Power Electronics, Vol. 18, No. 1, pp.301308 (2003-1)

[6] B.J.Patella, A.Prodic, A.Zirger, and D.Maksimovic: "Highfrequency digital PWM controller IC for DC-DC converters", IEEE Transactions on Power Electronics, Vol. 18 (2003-1)

[7] D.Maksimovic, R.Zane, and R. Erickson: "Impact of Digital Control in Power Electronics", IEEE International Symposium on Power Semiconductor Devices \& ICs, Kitakyushu, Japan, pp. 13-22 (2004-5)

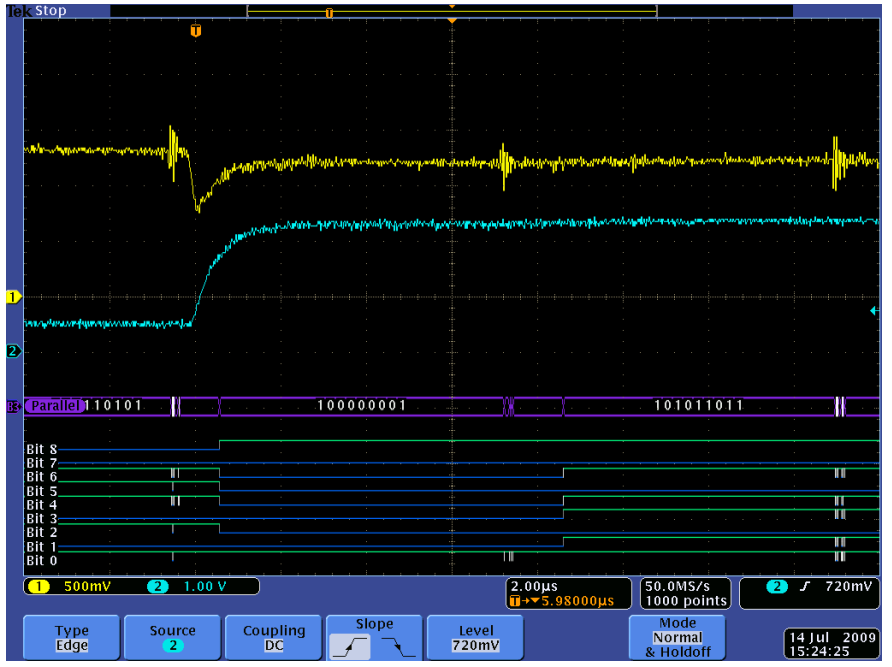

(b) $\mathrm{H}: 2 \mu \mathrm{s} / \mathrm{div}$.

Figure 9. Dynamic characteristics (from $0.5 \mathrm{~A}$ to $2.5 \mathrm{~A}$ )
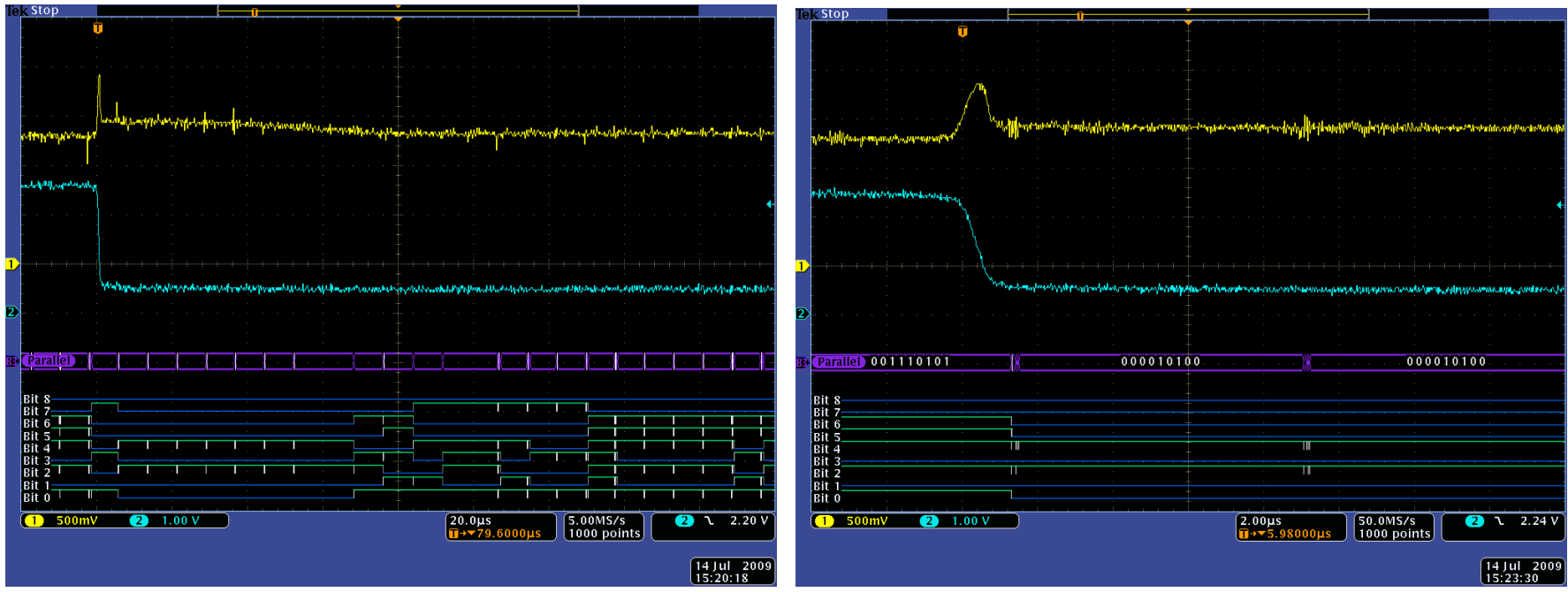

(a) $\mathrm{H}: 20 \mu \mathrm{s} / \mathrm{div}$

(b) $\mathrm{H}: 2 \mu \mathrm{s} / \mathrm{div}$.

Figure 10. Dynamic characteristics (from 2.5A to $0.5 \mathrm{~A}$ ). 
[8] Kaiwei Yao: "High-Frequency and High-Performance VRM Design for the Next Generation of Processors", Doctor thesis of Virginia Polytechnic Institute and State University (2004-4)

[9] S.Saggini, D.Trevisan, and P.Mattavelli: "Hysteresis-Based Mixed-Signal Voltage-Mode Control for dc-dc Converters", IEEE Power Electronics Conference (PESC'07), Orlando, Florida (2007-6)

[10] S.Saggini, E.Orietti, P.Mattavelli , A.Pizzutelli , and.Bianco: "Fully-Digital Hysteretic Voltage-Mode Control for dc-dc Converters based on Asynchronous Sampling”, IEEE Applied Power Electronics Conference (APEC'08), Austin, Texas (2008-2)

[11] G.F.Franklin, J.D.Powell, and M.L.Workman: "Digital Control of Dynamic Systems", Addison Wesley Longman Press, Menlo Park. CA (1997) 